\title{
Mecanismo de infecção de Colletotrichum spp. em flores de feijoa
}

\section{Mechanism of infection of Colletotrichum spp. on feijoa flowers}

\author{
Vinícius Spolaor Fantinel \\ Universidade Federal de Santa Maria \\ E-mail: vinispofan@hotmail.com \\ OrcID: https://orcid.org/0000-0002-0414-7486
}

Marlove Fátima Brião Muniz

Universidade Federal de Santa Maria

E-mail: marlovemuniz@yahoo.com.br

OrcID: https://orcid.org/0000-0001-7436-9589

\begin{abstract}
Tales Poletto
Universidade Federal de Santa Maria

E-mail: tecnicotales@hotmail.com

OrcID: https://orcid.org/0000-0002-6162-4445
\end{abstract}

Marlise Nara Ciotta

Empresa de Pesquisa Agropecuária e Extensão Rural de Santa Catarina

E-mail: marlise@epagri.sc.gov.br

OrclD: https://orcid.org/0000-0002-9807-2912

Renata Fontana Favaretto

Universidade Federal de Santa Maria

E-mail: renataffavaretto@gmail.com

OrcID: https://orcid.org/0000-0002-9804-089X

Jaqueline Raquel Tomm Krahn

Universidade Federal de Santa Maria

E-mail: jaquetomm@hotmail.com

OrcID: https://orcid.org/0000-0001-8289-2126

Resumo: Feijoa sellowiana (O. Berg) O. Berg (Myrtaceae), popularmente conhecida como goiabeira-serrana ou feijoa, é uma frutífera nativa do sul do Brasil e Uruguai e seus frutos apresentam grande potencial econômico e alimentício. Considerando a necessidade da boa aparência do fruto para comercialização, as doenças são um problema na produção, pois interferem na qualidade e podem inviabilizar o consumo dos frutos in natura. Nesse sentido, a principal doença que atinge pomares de goiabeira-serrana e que pode levar a consideráveis perdas nas fases pré e pós-colheita é a antracnose, causada por fungos do gênero Colletotrichum. Os conhecimentos acerca das relações patógeno-hospedeiro, através da elucidação do(s) mecanismo(s) de infecção de Colletotrichum spp. nas cultivares de interesse comercial são fundamentais para o estabelecimento de estratégias eficientes para o controle da antracnose. Nesse sentido, o presente estudo teve como objetivo verificar a incidência de Colletotrichum spp. em flores de goiabeira-serrana de quatro cultivares em diferentes estágios fenológicos de florescimento e constatar se o mecanismo de infecção deste patógeno ocorre de maneira sistêmica, via estruturas florais. Para a análise, foram selecionadas aleatoriamente 10 plantas adultas, das quais foram coletadas 100 flores para cada um dos estágios fenológicos de floração: B, E, $F_{2}$ e H por cultivar ("Alcântara", "Helena", "Mattos" e "Nonante"). As maiores incidências média de Colletotrichum spp. ocorreram no último estágio floral analisado $(H)$. A incidência do patógeno em flores de goiabeira-serrana indica que a infecção do patógeno ocorre de maneira sistêmica via peças florais, desde a formação do fruto.

Palavras-chave: Antracnose. Estruturas florais. Feijoa sellowiana. Incidência fúngica. 
Abstract: Feijoa sellowiana (O. Berg) O. Berg (Myrtaceae), popularly known as mountain guava or feijoa, is a fruit native to southern Brazil and Uruguay and its fruits have great economic and food potential. Considering the need for a good appearance of the fruit for commercialization, diseases are an obstacle to production, as they interfere with quality and can make the consumption of fresh fruits unfeasible. In this sense, the main disease that affects feijoa orchards and which can lead to considerable losses in the pre and post-harvest phases is anthracnose, caused by fungi of the genus Colletotrichum. The knowledge about host-pathogen relationships, by elucidating the mechanism(s) of infection of Colletotrichum spp. in cultivars of commercial interest are fundamental for the establishment of efficient strategies for the control of anthracnose. In this sense, the present study aimed to verify the incidence of Colletotrichum spp. in feijoa flowers of four cultivars in different flowering phenological stages and see if the infection mechanism of this pathogen occurs systemically, via floral structures. For the analysis, 10 adult plants were randomly selected, from which 100 flowers were collected for each of the flowering phenological stages: B, E, F $F_{2}$ and H per cultivar ("Alcântara", "Helena", "Mattos" and "Nonante"). The highest mean incidences of Colletotrichum spp. occurred in the last analyzed floral stage $(\mathrm{H})$. The incidence of the pathogen in feijoa flowers indicates that infection of the pathogen occurs systemically via floral parts, since the formation of the fruit.

Keywords: Anthracnosis. Feijoa sellowiana. Fungal incidence. Floral structures.

Data de recebimento: $11 / 05 / 2020$

Data de aprovação: 03/03/2021

DOI: https://doi.org/10.30612/agrarian.v14i52.11899

\section{Introdução}

A espécie Feijoa sellowiana (O. Berg) O. Berg, popularmente conhecida por feijoa, goiaba-serrana, goiabeira-serrana, goiaba do campo ou goiaba da serra é uma espécie frutífera de grande interesse econômico e, por isso, está em intenso processo de domesticação (Amarante et al., 2011). No Brasil, a ocorrência da goiabeira-serrana concentra-se nas regiões fisiográficas da Serra do Sudeste, Planalto Médio e Campos de Cima da Serra no Rio Grande do Sul, no Planalto Serrano Catarinense e Campos de Altitude do Paraná, onde habita a orla da mata e vegetações de fisionomia savânica (Wagner, 2020).

Além dos frutos, as pétalas das flores podem ser destinadas para consumo humano (decoração de pratos, saladas, doces) em razão do seu agradável sabor e seu colorido intenso. As flores são formadas por quatro pétalas subcarnosas, avermelhadas por dentro e cerosas por fora, estames de cor escarlate, saindo até $2 \mathrm{~cm}$ acima da flor e estigma ligeiramente engrossado (Souza, 2016).

Os principais prejuízos para a cultura, considerando o aspecto fitossanitário, são decorrentes da antracnose, doença fúngica causada por espécies dos complexos Colletotrichum gloeosporioides, Colletotrichum acutatum e Colletotrichum pseudoacutatum (Fantinel, 2020). Fungos do gênero Colletotrichum, além de infectarem os frutos, são responsáveis pela podridão do pedúnculo e podem gerar perdas de até $100 \%$ em plantas em plena frutificação (Araújo \& Pinto, 2018).

Fantinel et al. (2017a) identificaram Colletotrichum siamense patogênico à goiabeira-serrana causando manchas nos frutos de coloração escuras bem definidas de formato irregular que, após aumentarem de tamanho, se tornaram deprimidas e coalescidas, levando os frutos ao apodrecimento e, consequentemente, ocasionando diminuição de produtividade nos pomares.

Uma das características importantes de Colletotrichum spp. é a sua capacidade de sobreviver em estado de quiescência nas flores e nos frutos. A ocorrência e a manutenção do patógeno em quiescência sobre o hospedeiro ou dentro do mesmo indicam um equilíbrio dinâmico entre hospedeiro, patógeno e meio ambiente (Jarvis, 1994).

Conforme descrevem Agarwal e Sinclair (1996), a infecção de um patógeno em um determinado hospedeiro pode ocorrer principalmente através de duas maneiras: a) infecção local - via pericarpo e tegumento (no fruto) ou b) via sistêmica - através da flor, tanto através do sistema vascular pelo pedicelo, ou pela colonização de estigmas, seguindo até a semente via tubo polínico. Considerando a goiabeira-serrana, não se conhece, até o momento, o mecanismo de infecção de Colletotrichum spp., a despeito do que ocorre com a goiaba-comum (Psidium guajava L.), onde a penetração de Colletotrichum spp. ocorre tanto via ferimentos no fruto como também pela cavidade floral (Junqueira et al., 2001). 
Estudos que envolvam o processo infeccioso de Colletotrichum spp., poderão ajudar no desenvolvimento de estratégias eficientes de controle da antracnose em pomares de goiabeira-serrana de modo a evitar que os danos, em decorrência da doença, resultem na erradicação desta cultura que, cultivada em pequenas propriedades, apresenta grande importância social e econômica nas regiões em que seu plantio é difundido.

Nesse sentido, buscou-se através do presente estudo, verificar a incidência de Colletotrichum spp. em flores de goiabeira-serrana das quatro cultivares comerciais: "Alcântara", "Helena", "Mattos e "Nonante" em quatro estágios fenológicos de florescimento e constatar se o mecanismo de infecção deste patógeno acontece de maneira sistêmica, via estruturas florais.

\section{Material e Métodos}

Foram coletadas flores sadias, sem sintomas de antracnose, na safra de 2017/2018 das quatro cultivares com potencial comercial: "Alcântara", "Helena", "Mattos" e "Nonante" nos dois Bancos Ativos de Germoplasma (BAG) de goiabeira-serrana existentes no Brasil. Os BAG's pertencem a EPAGRI e estão localizados no município de São Joaquim (SC), localizado em uma altitude de $1415 \mathrm{~m}$, latitude $28^{\circ} 17^{\prime} 25^{\prime \prime} \mathrm{S}$ e longitude $49^{\circ} 56^{\prime} 56^{\prime \prime}$ W e no município de Lages (SC) com altitude de $926 \mathrm{~m}$, latitude $27^{\circ} 48^{\prime} 27.6^{\prime \prime S}$ e longitude $50^{\circ} 19^{\prime} 46.3^{\prime \prime} \mathrm{W}$.

Em cada pomar das estações experimentais da EPAGRI dos municípios de Lages/SC e São Joaquim/SC, foram selecionadas aleatoriamente 10 goiabeiras-serrana de cada Cv.: "Alcântara", "Helena", "Mattos" e "Nonante" onde foram coletadas 100 flores sem sintomas aparentes de antracnose nos estágios fenológicos de florescimento B, E, $F_{2}$ e H (Ducroquet \& Hickel, 1991) (Figura 1).

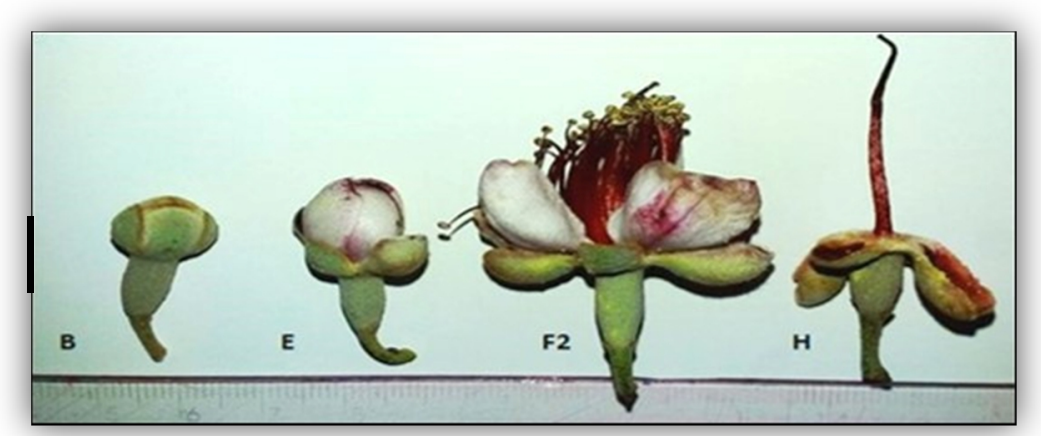

Figura 1. Estágios fenológicos de florescimento de goiabeira-serrana. B: Botão floral fechado, E: Desabrochar das peças florais, $\mathrm{F}_{2}$ : Flor completa após antese, $\mathrm{H}$ : Flor com estilete já com pétalas caídas. Barra $=0,5 \mathrm{~cm}$.

As amostras de flores foram avaliadas pelo método de "Blotter Test", para isto, foram desinfestadas através da imersão em solução de hipoclorito de sódio $2 \%$ e água destilada e esterilizada por 1 min. (Poletto et al., 2014).

Em seguida, as flores foram acondicionadas em caixas plásticas do tipo Gerbox $(11,0 \times 11,0 \times 3,5 \mathrm{~cm})$ dispostas sobre papel-filtro umedecido em água destilada e esterilizada.

$O$ delineamento experimental foi o inteiramente casualizado e os tratamentos foram compostos pelos estágios de desenvolvimento floral com 100 flores, divididas em quatro repetições de 25 . As flores foram incubadas e mantidas em câmara de crescimento a $25 \pm 2{ }^{\circ} \mathrm{C}$, sob fotoperíodo de 12 horas por um período de sete dias (Poletto et al., 2014).

A avaliação foi realizada com auxílio de microscópio estereoscópico e óptico aos sete dias para a visualização das estruturas do patógeno em qualquer parte da flor e a identificação do fungo foi realizada com o auxílio da chave de identificação (Barnett e Hunter, 1999).

Fungos do gênero Colletotrichum foram contabilizados, expressos em porcentagem e transformados por ARCSEN $[(x+0,5) /(100)] \frac{1}{2}$ para normalização, em seguida, submetidos à análise de variância. Em caso de significância, as médias dos tratamentos foram comparadas pelo teste de Tukey a $5 \%$ de probabilidade de erro. Para estas análises, utilizou-se o programa estatístico SISVAR versão 5.6 (Ferreira, 2015).

\section{Resultados e Discussão}


Foi possível constatar a incidência de Colletotrichum spp. infectando flores de goiabeira-serrana nas fases $B, E, F_{2}$ e H em ambos os locais de coleta (Lages e São Joaquim). Considerando a procedência Lages, a maior incidência média de Colletotrichum spp. ocorreu na cv. "Alcântara" independentemente do estágio floral analisado (32,5\%). O estágio B apresentou a menor incidência média de Colletotrichum spp. entre as cultivares de goiabeira-serrana (3,25\%), seguido dos estágios E e $F_{2}$ com 9 e 23,25\%, respectivamente. $O$ estágio $\mathrm{H}$ diferiu dos demais nas duas procedências analisadas apresentando a maior incidência média de Colletotrichum spp. (74,25\%) (Tabela 1).

A menor incidência média de Colletotrichum spp. ocorreu para a cv. "Helena" independentemente do estágio floral analisado (25\%), seguido das cvs. "Mattos" e "Nonante" com 25,5 e 26,75\%, respectivamente.

Tabela 1. Incidência (\%) de Colletotrichum spp. em flores de goiabeira-serrana em diferentes estágios fenológicos de florescimento oriundas de Lages (SC), submetidas ao teste de sanidade através do método de "Blotter Test".

\begin{tabular}{cccccc}
\hline \multirow{2}{*}{ Estágios Florais } & \multicolumn{3}{c}{ Cultivares } & \multirow{2}{*}{ Média } \\
\cline { 2 - 5 } & Helena & Mattos & Nonante & Alcântara & \\
\hline $\mathrm{B}$ & $5,0 \mathrm{Ac} c^{*}$ & $3,0 \mathrm{Ac}$ & $0,0 \mathrm{Bd}$ & $5,0 \mathrm{Ac}$ & 3,2 \\
$\mathrm{E}$ & $8,0 \mathrm{Ac}$ & $7,0 \mathrm{Ac}$ & $9,0 \mathrm{Ac}$ & $12,0 \mathrm{Ab}$ & 9,0 \\
$\mathrm{~F}_{2}$ & $25,0 \mathrm{Ab}$ & $16,0 \mathrm{Bb}$ & $29,0 \mathrm{Ab}$ & $23,0 \mathrm{Ab}$ & 23,2 \\
$\mathrm{H}$ & $62,0 \mathrm{Ba}$ & $76,0 \mathrm{Ba}$ & $69,0 \mathrm{Ba}$ & $90,0 \mathrm{Aa}$ & 74,2 \\
\hline Média & 25,0 & 25,5 & 26,7 & 32,5 & \\
\hline CV (\%) & & \multicolumn{2}{c}{25,0} & \\
\hline
\end{tabular}

* Médias seguidas por mesma letra maiúscula na linha e minúscula na coluna não diferem entre si pelo teste de Tukey ao nível de $5 \%$ de probabilidade.

Da mesma maneira, quando foram analisadas flores coletadas no município de São Joaquim, a cv. "Alcântara" apresentou maior incidência média de Colletotrichum spp. independentemente do estágio floral analisado (38\%), enquanto a cv. com menor incidência média de Colletotrichum spp. foi "Mattos" $(26,5 \%)$, seguida de "Nonante" e "Helena". O estágio H diferiu dos demais em todas as procedências analisadas com incidência média de (88\%) (Tabela 2).

Tabela 2. Incidência (\%) de Colletotrichum spp. em flores de goiabeira-serrana em diferentes estágios fenológicos de florescimento oriundas de São Joaquim (SC), submetidas ao teste de sanidade através do método de "Blotter Test".

\begin{tabular}{cccccc}
\hline \multirow{2}{*}{ Estágios Florais } & \multicolumn{3}{c}{ Cultivares } & \multirow{2}{*}{ Média } \\
\cline { 2 - 5 } & Helena & Mattos & Nonante & Alcântara & 2,2 \\
$\mathrm{~B}$ & $5,0 \mathrm{Ac}{ }^{*}$ & $0,0 \mathrm{Bc}$ & $2,0 \mathrm{Ab}$ & $2,0 \mathrm{Ac}$ & 9,7 \\
$\mathrm{E}$ & $9,0 \mathrm{Ac}$ & $6,0 \mathrm{Bb}$ & $10,0 \mathrm{Ab}$ & $14,0 \mathrm{Ab}$ & 22,7 \\
$\mathrm{~F}_{2}$ & $17,0 \mathrm{Bb}$ & $10,0 \mathrm{Cb}$ & $24,0 \mathrm{Bb}$ & $40,0 \mathrm{Ab}$ & 86,0 \\
$\mathrm{H}$ & $86,0 \mathrm{Aa}$ & $90,0 \mathrm{Aa}$ & $80,0 \mathrm{Aa}$ & 38,0 & \\
\hline Média & 29,2 & 26,5 & 29,0 & & \\
\hline CV (\%) & \multicolumn{5}{c}{36,0}
\end{tabular}

* Médias seguidas por mesma letra maiúscula na linha e minúscula na coluna não diferem entre si pelo teste de Tukey ao nível de $5 \%$ de probabilidade.

A maior incidência média de Colletotrichum spp. em flores da cv. "Alcântara" pode estar relacionada com o fato dessa cultivar ser suscetível à antracnose quando comparada com as demais cultivares com potencial comercial, conforme estudo realizado por Fantinel (2020).

Seguindo essa premissa, a cv. "Mattos" que apresentou a menor incidência média de Colletotrichum spp. nas flores, foi a que se mostrou resistente à antracnose para $C$. nymphaeae, C. theobromicola, $C$. fructicola e C. pseudoacutatum (Fantinel, 2020).

Considerando os estágios fenológicos de florescimento, as maiores infecções por Colletotrichum spp. se deram no último estágio floral analisado $(\mathrm{H})$ para ambas as procedências (Lages e São Joaquim). Este resultado, pode estar relacionado com o maior tempo de permanência dessas flores (em estágio mais avançado de florescimento) nos locais de coleta.

O processo de infecção de Colletotrichum spp. pode ocorrer durante o período de floração onde pétalas e anteras são infectadas e o patógeno passa a se desenvolver até atingir as sépalas e o receptáculo. 
Como estas partes florais estão diretamente em contato com os frutos, acabam infectando-o e provocando seu apodrecimento nas fases pré e pós-colheita.

Poletto et al. (2014) em estudo conduzido com fungos associados a flores de nogueira-pecã (Carya illinoinensis), evidenciaram a importância do conhecimento dos patógenos que se associam com as flores, na medida que os mesmos podem infectar os frutos, e levar a perdas diretas na produção.

De fato, em vários outros patossistemas, as flores são consideradas porta de entrada de muitos patógenos, que posteriormente, podem infectar os frutos. Como ocorre nos citros (Citrus spp.) onde a ocorrência da podridão floral dos citros (PFC), causada pela infecção de flores por Colletotrichum acutatum, acarreta a abscisão de frutos jovens (Silveira et al., 2016).

Segundo Serra et al. (2011), que estudaram a antracnose em mangueira (Mangifera indica L.), os períodos críticos de infecção de Colletotrichum spp. correspondem justamente as fases de florescimento. Em inflorescências, os sintomas se iniciam com pontuações escuras, que se tornam alongadas e profundas e provocam a morte de flores e queda de frutos.

Na cultura do morangueiro (Fragaria $x$ ananassa Duch.), a incidência de Colletotrichum spp. em flores acarreta uma doença conhecida como flor preta. Os sintomas em condições de campo são a necrose progressiva dos pedúnculos e demais partes dos órgãos florais, culminando com a seca e morte das flores. Os frutos pequenos e em crescimento também podem ser atacados adquirindo coloração escura e tornam-se mumificados (Wilson et al., 1993).

Carvalho e Amaral (2018) identificaram Colletotrichum spp. associados a botões florais de pequizeiro (Caryocar Brasiliense), causando lesões necróticas nas flores, tornando inviável a produção de frutos. Fischer et al. (2019) em estudo de epidemiologia em abacateiro (Persea americana), detectaram após cinco dias de incubação, acérvulos e conídios de Colletotrichum spp. causando lesões típicas de antracnose, abortamento de flores e infecções quiescentes em abacates.

No presente trabalho, no momento da coleta, nenhuma flor de goiabeira-serrana apresentava sintoma aparente de antracnose. No entanto, como o patógeno foi identificado posteriormente em testes laboratoriais, pode-se inferir que ele se encontrava em período de quiescência/latência ou ainda de maneira endofítica.

Fungos do gênero Colletotrichum são comumente conhecidos por apresentar esse tipo de estratégia (Delgado Méndez, 2016). Não se tem conhecimento a respeito do tempo de duração da fase de quiescência em flores e frutos de goiabeira-serrana. Para a cultura da maçã (Malus spp.), a fase quiescente de Colletotrichum spp. que infecta flores pode variar de duas a três semanas, enquanto para os frutos, essa fase pode durar vários meses (Delgado Méndez, 2016).

De acordo com Moraes et al. (2015), as etapas iniciais da infecção pelas espécies de Colletotrichum são bastante similares. Primeiramente, o conídio aderido à superfície do hospedeiro germina, o tubo germinativo cresce e se desenvolve formando um micélio que forma um conídio secundário ou apressório. Esta forma um 'peg' de penetração que invade diretamente a cutícula e a parede das células. Há dois tipos de estratégias de colonização por espécies de Colletotrichum: intracelular hemibiotrófico e subcuticularintramural necrotrófico. Os patógenos com estratégia intracelular hemibiotrófica invadem as células por um período curto mantendo-as vivas, aparentemente, para a sua nutrição, e então convertem para a fase necrotrófica, matando a célula (Perfect et al., 1999).

Pode-se inferir que no presente trabalho, na medida em que o patógeno encontrou condições favoráveis de temperatura e umidade para seu desenvolvimento (condições de incubação), o período de latência foi superado e o mesmo passou a apresentar os seus sinais.

A infecção de Colletotrichum spp. em flores de goiabeira-serrana das cvs. "Alcântara", "Helena", "Mattos" e "Nonante" foi confirmada pela sua esporulação em pétalas, ovário, óvulos e estames em flores nos estágios $E$ e $F_{2}$ aos sete dias de incubação. No estágio $H$ de fenologia floral foi verificada a presença de Colletotrichum spp. infectando os estiletes bem como sépalas e os frutos formados (Figura 2). 


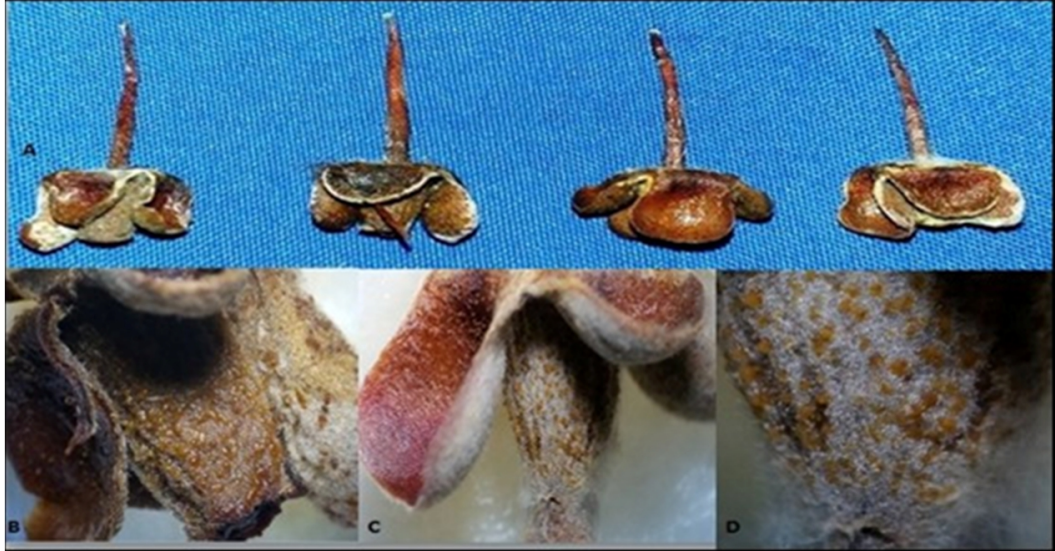

Figura 2. Incidência de Colletotrichum spp. em flores de goiabeira-serrana em estágio $\mathrm{H}$ de fenologia floral. A: Infecção de Colletotrichum spp. em sépalas e estilete de flores. B/C/D: Incidência de Colletotrichum spp. em frutos, no detalhe os pontos alaranjados são acérvulos de Colletotrichum spp.. Barra $=0,5 \mathrm{~cm}$.

Flores nestas condições, possivelmente não produzirão frutos, ou mesmo que haja produção, os mesmos não serão saudáveis. Os mesmos sintomas presentes nas flores apresentadas na Figura 2 foram descritos por Blood et al. (2015), que confirmaram a infecção de Colletotrichum spp. em flores de caquizeiro das cvs. "Fuyu" e "Kakimel" através da esporulação em ovários e na base das sépalas.

O conhecimento acerca do mecanismo de infecção de Colletotrichum spp. em goiabeira-serrana é fundamental e auxilia no desenvolvimento de estratégias de controle da antracnose uma vez que os sintomas causados por este patógeno se desenvolvem principalmente em pós-colheita (com o fruto maduro), mas refletem, todavia, os fatores que ocorreram em pré-colheita, como, por exemplo, os tratos culturais incorretos.

É importante salientar que segundo Fantinel et al. (2017c) a principal forma de propagação de goiabaserrana é via sexuada (seminal), principalmente quando as mudas são utilizadas para a produção de portaenxertos na qual são enxertadas as cvs. de interesse comercial.

Considerando que a infecção de Colletotrichum spp. em goiabeira-serrana ocorre de maneira sistêmica, via estruturas florais, e que em estudos anteriores Fantinel et al. (2017b) constataram a transmissão deste patógeno via semente para plântula, é provável que este fungo infecte as sementes já no processo de formação delas, através dos óvulos. No entanto, o sucesso de Colletotrichum spp. como agentes patogênicos é determinado, quase exclusivamente, pelo modo como infectam e colonizam os tecidos hospedeiros. Os seus modos de ação são muito variáveis, indo desde o endofítico até ao necrotrófico e têm sido alvo de extensas revisões (De Silva et al., 2017).

Uma vez que o ciclo de vida de Colletotrichum spp. em goiabeira-serrana não é bem esclarecido (Araújo e Pinto, 2018), sugere-se, com o presente estudo, que a fonte inóculo de Colletotrichum spp. em pomares de goiabeira-serrana, em área sem histórico de ocorrência da antracnose, pode ser proveniente de sementes infectadas pelo patógeno através das estruturas florais (Figura $3 a$ e 3b).

$\mathrm{Na}$ fase de floração, as flores podem ser infectadas e permanecer infectadas assintomaticamente desde os estádios iniciais de floração até ao desenvolvimento dos frutos. É possível que isolados de Colletotrichum spp. estejam presentes no cálice, pétalas, estames e pistilo das flores, sendo capazes de esporular (Figuras 2 e 3 ).

Nas áreas onde já ocorreu a doença, a fonte de inóculo primário pode ser o próprio solo ou restos de cultura, como frutos infectados ou mumificados (Figura 3e e 3f), onde o patógeno consegue sobreviver por um longo período. Com o desenvolvimento da doença, as mudas infectadas, as flores e os frutos mumificados servirão como fonte de inóculo para outras plantas (Figura 3b, 3d e 3f) 


\section{Pagrarian}

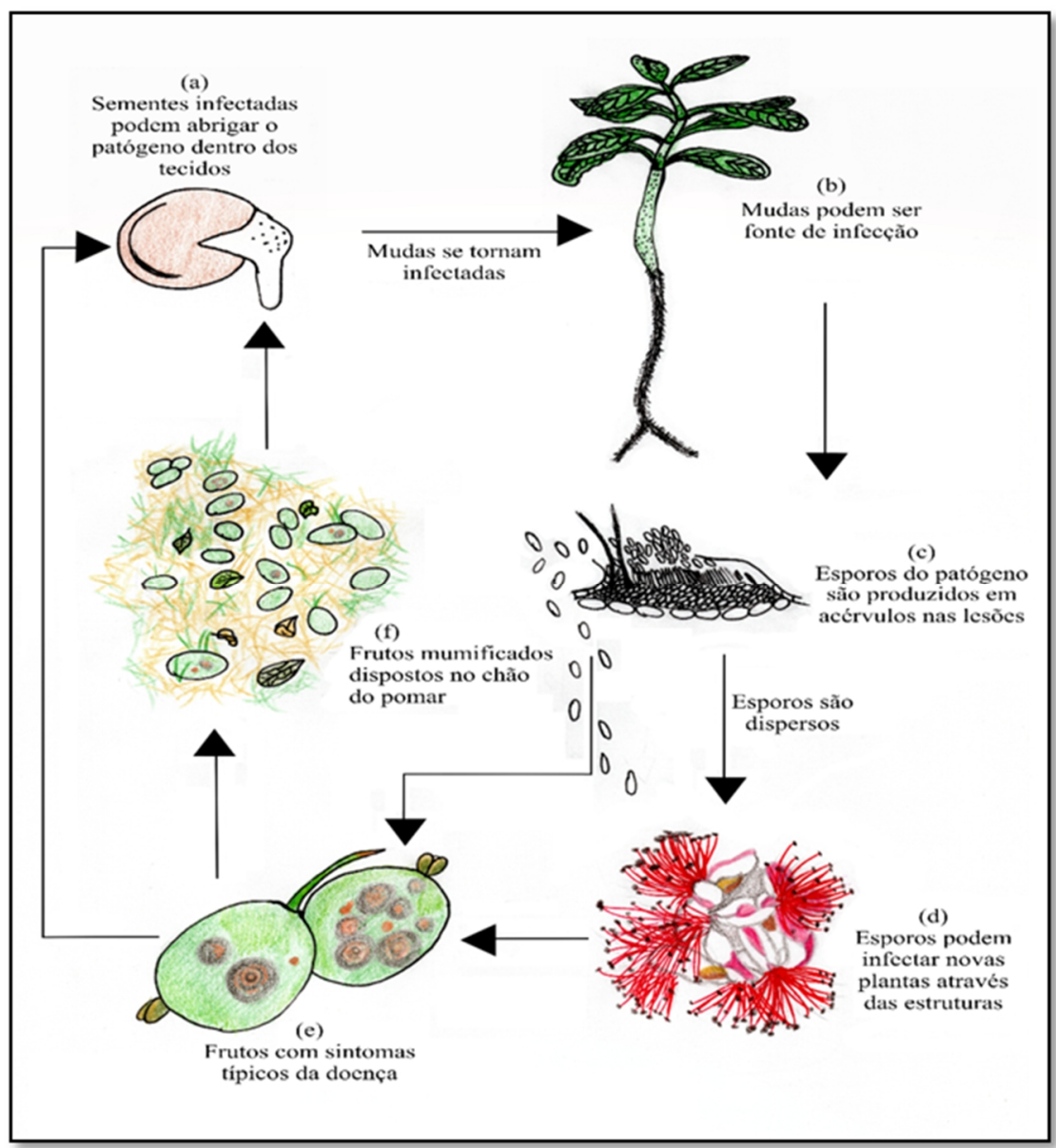

Figura 3. Ciclo da antracnose em Feijoa sellowiana (O. Berg) O. Berg. causada por Colletotrichum spp.

A disseminação do patógeno pode ser rápida quando não é feito o controle efetivo da doença. Nesse sentido, a utilização de métodos culturais, através da remoção de flores e frutos doentes/mumificados, pode reduzir a pressão do inóculo dentro dos pomares.

Enfim, o conhecimento acerca da variabilidade dos isolados de Colletotrichum predominantes em goiabeira-serrana, através da análise multigênica, bem como a utilização de cultivares preferenciais do ponto de vista fitossanitário são fundamentais, pois fornecem subsídios para a construção de modelos epidemiológicos mais detalhados que possam, em breve, ser aplicados por melhoristas para a implementação de estratégias de controle da doença.

\section{Conclusão}

O mecanismo de infecção de Colletotrichum spp. ocorre de forma sistêmica via estruturas florais,

$\mathrm{O}$ estágio $\mathrm{H}$ de fenologia floral apresentou a maior incidência de Colletotrichum spp,

As cvs. "Alcântara" e "Mattos" apresentaram a maior e a menor incidência média de Colletotrichum spp. respectivamente.

\section{Agradecimentos}

À coordenação de Aperfeiçoamento de Pessoal de Nível Superior (CAPES) pela bolsa concedida e ao Concelho Nacional de Desenvolvimento Científico e Tecnológico (CNPQ) pela Bolsa de Produtividade em pesquisa (PQ) para Marlove Fátima Brião Muniz.

\section{Referências}


Agarwal, V.K., Sinclair, J.B. (1996). Principles of seed pathology. Boca Raton: CRC Press.

Amarante C.V.T. \& Santos K.L. (2011). Goiabeira-serrana (Acca sellowiana). Revista Brasileira de Fruticultura, 33(1):1-2.

Araújo, L. \& Pinto, F.A.M.F. (2018). Principais doenças e seu controle. In: Ciotta, M.N., Arioli, C.J., Pinto, F.A.M.F., Santos, K., Araujo, L., Pasa, M.S. (Orgs.). A cultura da goiabeira-serrana. Florianópolis: Epagri, p. 147-166.

Barnett, H.L. \& Hunter, B.B. (1990). Illustred genera of imperfect fungi. 3. ed. Minnesota: Burgess Publishing Company.

Blood, R.R.Y., Rozwalka, L.C., May de mio, L.L. (2015). Antracnose do caquizeiro causada por Colletotrichum horii: incidência em ramos, folhas, flores e frutos em campo. Revista Brasileira de Fruticultura, 37(2), 335-345. https://doi.org/10.1590/0100-2945-108/14.

Carvalho, F.J. \& Amaral, D.R. (2018) Ocorrência de antracnose em pequizeiro na região do triângulo mineiro, Minas Gerais. Agrarian Academy, 5(9), 422-428.

De Silva, D.D., Crous, P.W., Ades, P.K., Hyde, K.D., Taylor, P.W.J. (2017). Life styles of Colletotrichum species and implications for plant biosecurity. Fungal Biology Reviews, 31(3). 155-168.

https://doi.org/10.1016/i.fbr.2017.05.001.

Delgado Méndez, D.Z. Caracterização da patogenicidade de isolados de Colletotrichum fructicola em frutos de macieira (Malus domestica Borkh.) em diferentes estágios de desenvolvimento. (2016). 127 f. Tese (Doutorado em Recursos Genéticos Vegetais) - Universidade Federal de Santa Catarina, Florianópolis.

Ducroquet, J.P.H.J. \& Hickel, E.R. (1991). Fenologia da goiabeira serrana (Feijoa sellowiana Berg) no alto vale do Rio do Peixe, Santa Catarina. Revista Brasileira de Fruticultura, 13(3), 313-320.

Fantinel, V.S., Muniz, M.F.B., Blume, E., Araújo, M.M., Poletto, T., Da Silva, T.T., Harakava, R. (2017a). First report of Colletotrichum siamense causing anthracnose on Acca sellowiana fruits in Brazil. Plant

Disease, 101(6), 1035.

Fantinel, V.S., Oliveira, L.M., Casa, R.T., Rocha, E.C., Schneider, P.F., Pozzan, M., Liesch, P.P., Ribeiro, R.A. (2017b). Fungos associados às sementes de Acca sellowiana: efeitos na qualidade fisiológica das sementes e transmissão. Agrarian, 10(38). 328-335, https://doi.org/10.30612/agrarian.v10i38.4509.

Fantinel, V.S., Oliveira, L.M., Casa, R.T., Schneider, P.F., Rocha, E.C., Vicente, D., Pozzan, M. (2017c). Detecção de fungos em sementes de Acca sellowiana (Berg) Burret. Floresta e Ambiente, 24(1), 1-11. https://doi.org/10.1590/2179-8087.087414.

Fantinel, V.S. (2020). Caracterização do Patossistema Colletotrichum spp./goiabeira-serrana. 157 f. Tese (Doutorado em Engenharia Florestal) - Universidade Federal de Santa Maria, Santa Maria.

Ferreira, D.F. Sisvar. Versão 5.6. Lavras: UFLA/DEX, 2015. Disponível em:< http://www.dex.ufla.br/ danielff/programas/sisvar.html>. Acesso em: 16/01/2020.

Fischer, I.H., Moraes, M.F., Firmino, A.C., Amorim, L. (2019). Detection and epidemiological progress of quiescent avocado diseases. Ciência Rural, 49(8), 1-10. https://doi.org/10.1590/0103-8478cr20180731.

Jarvis, W.R. Latent infections in the pre and postharvest environment. (1994) HortScience, 29(7), 749-751.

Junqueira, N.T.V., Andrade, L.R.M., Pereira, M., Lima, M.M., Chaves, R.C. (2001) Doenças da goiabeira no cerrado. Planaltina: Embrapa Cerrados.

Moraes, S.R.G., Escanferla, M.E., Massola Junior,N.S. (2015). Pre penetration and Penetration of Colletotrichum gloeosporioides into guava fruit (Psidium guajava L.): Effects of Temperature, Wetness Period and Fruit Age. Journal of Phytopathogy, 163(1). 149-159, https://doi.org/10.1111/iph.12294.

Poletto, T., Muniz, M.F.B., Baggiotto, C., Ceconi, D.E., Poletto, I. (2014). Fungos associados às flores e frutos da nogueira-pecã (Carya illinoinensis). Revista de Ciências Ambientais, 8(1), 5-13,

http://dx.doi.org/10.18316/1384. 


\section{PAGRARIAN}

Serra, I.M.R.S., Coelho, R.S.B., Ferraz, G.M.G., Montarroyos, V.V., Silva, D.S. (2011) Diversidade fenotípica e patogênica de Colletotrichum, agente causal da antracnose em mangueira e identificação de espécie. Summa phytopathologica, 37(1). 42-51. https://doi.org/10.1590/S0100-54052011000100007.

Silveira, A.L., Stracieri, J., Pereira, F.D., Souza, A., Goes, A.D. (2016). Caracterização molecular de isolados de Colletotrichum spp. associados a podridão floral dos citros. Revista Brasileira de Fruticultura, 38(1). 64-71. https://doi.org/10.1590/0100-2945-041/15.

Souza, A.G., Amarante, C.V.T., Steffens, C.A., Benincá, T.D.T., Padilha, M. (2016). Postharvest quality of feijoa flowers treated with different preservative solutions and 1-methylcyclopropene. Revista Brasileira de Fruticultura, 38(1). 759. https://doi.org/10.1590/0100-29452016759.

Wagner, M.A. \& Fiaschi, P. (2020) Myrtaceae from the Atlantic forest subtropical highlands of São Joaquim National Park (Santa Catarina, Brazil). Rodriguésia, 71(1). https://doi.org/10.1590/2175-7860202071006.

Wilson, L.L., Madden, L.V., Ellis, M.A. (1993). Comparison of conidial germination and strawberry fruit infection by three Colletotrichum species. Phytopathology, 83(12), p. 1390. 